\title{
Strategi Pengembangan Perikanan Tangkap di Kabupaten Bangka Selatan
}

\author{
Capture Fisheries Development Strategy in South Bangka Regency
}

\author{
Kurniawan $^{1}$ \\ ${ }^{1}$ Dosen Jurusan Manajemen Sumberdaya Perairan FPPB-UBB, Balunijuk \\ Ketua Pusat Kajian Sumberdaya Perairan dan Pulau-Pulau Kecil, Lembaga Penelitian dan Pengembangan Masyarakat \\ Universitas Bangka Belitung \\ awal.rizka@yahoo.com
}

Diterima Agustus; disetujui September tersedia secara online November

\begin{abstract}
Capture fishery in South Bangka Regency has the prospect to be developed as one of the leading sectors in regional economic development. The purpose of this research is to know and provide fish resource development plan in South Bangka Regency. The method used is descriptive method, with the taking of survey data, survey and study of relevant literature. SWOT analysis was conducted to make capture fisheries development strategy in South Bangka Regency. The results showed that South Bangka Regency has potential of fishery potential. While capture fisheries development strategy in South Bangka Regency are social, economic and sustainable development strategy, human resources strategy and development, promotion strategy for potential resources for development and development of facilities and infrastructure. supporters of fisheries development.
\end{abstract}

Keywords: Development Strategy, Capture Fishery,South Bangka Regency

\section{PENDAHULUAN}

Kabupaten Bangka Selatan merupakan daerah yang disahkan pada tahun 2003 berdasarkan UU No. 5 tahun 2003 atas pemekaran wilayah Provinsi Kepulauan Bangka Belitung. Daerah ini memiliki potensi unggulan di bidang perikanan setelah pertanian dan perkebunan. Sektor perikanan merupakan potensi yang besar untuk dikembangkan dan dijadikan sebagai salah satu prime mover pembangunan suatu daerah. Wilayah pengelolaan perikanan di Kabupaten Bangka Selatan memiliki potensi yang cukup besar untuk dikembangkan, mengingat wilayah ini berhadapan langsung dengan laut lepas. Potensi perikanan di Kabupaten Bangka Selatan terdiri dari potensi perikanan budidaya serta potensi perikanan laut.

Sumberdaya perikanan merupakan sumberdaya yang sifatnya terbatas dan dapat pulih kembali (renewable), yang berarti bahwa setiap pengurangan yang disebabkan kematian maupun penangkapan akan dapat memulihkan sumberdaya tersebut ke tingkat produktivitas semula (Pertiwi, 2011). Sumberdaya perikanan laut terdiri dari ikan pelagis dan ikan demersal. Berdasarkan data dari DPPP Kabupaten Bangka Selatan (2017), jumlah produksi penangkapan ikan laut di tahun 2012 mencapai 44.733,12 ton dengan nilai tangkapan laut sebesar Rp. 519.329,609, ditahun 2013 jumlah produksi sebesar 44.975,30 ton akan tetapi, pada tahun 2014 terjadi penurunan produksi sebesar 39.471,17 ton dengan nilai tangkapan ikan sebesar Rp. 1.075.284.255 dan meningkat kembali di tahun 2015 dengan jumlah produksi 50.302,02 ton dan di tahun 2016 sebesar 41,309,60 ton dengan nilai tangkapan ikan sebesar Rp.633.568.570. Hal ini menunjukkan bahwa jumlah produksi perikanan laut pada tahun 2012-2016 di perairan Kabupaten Bangka Selatan mengalami penurunan pada tahun 2014, penurunan produksi mecapai $10 \%$ dari jumlah produksi tahun sebelumnya maupun sesudahnya.

Dalam pemanfaatan sumberdaya pesisir di Kabupaten Bangka Selatan terdapat berbagai tekanan. Diantaranya gesekan dengan pemanfaatan sumberdaya pasir timah. Kegiatan penambangan pasir timah baik secara langsung ataupun tidak langsung memberikan tekanan yang signifikan terhadap kualitas air laut dan biota di wilayah pesisir (Kurniawan, 2013). Untuk itu, perlu adanya sebuah strategi dalam pengelolaan yang mengedepankan perinsip pemanfaatan perikanan berkelanjutan.

Besarnya potensi bidang perikanan tersebut seharusnya diiringi dengan pengelolaan dan strategi pengembangan yang tepat dalam rangka mewujudkan keseimbangan antara keadilan, pertumbuhan dan keberlanjutan. Berdasarkan hal tersebut, maka di perlukan sebuah rencana strategis pengembangan perikanan di Kabupaten Bangka Selatan yang diharapkan dapat menjadi pedoman pelaksanaan pembangunan perikanan secara berkelanjutan. Tujuan penelitian yaitu 
untuk menyediakan rencana strategi pengembangan perikanan tangkap dalam mewujudkan pembangunan perikanan di Kabupaten Bangka Selatan.

\section{METODE PENELITIAN}

Penelitian ini dilaksanakan pada bulan November 2017 hingga Februari 2018, bertempat di Kabupaten Bangka Selatan Provinsi Kepulauan Bangka Belitung.

Data yang diambil dalam penelitian ini adalah data primer dan data sekunder. Data primer diperoleh dari data kuisioner dari 160 nelayan yang terdapat di Kabupaten Bangka Selatan. Data yang di ambil meliputi jenis alat tangkap, kontruksi, volume kapal (GT) dan trip penangkapan setiap unit.

Tabel 1. Data primer yang diambil dalam penelitian

\begin{tabular}{|c|c|c|}
\hline No. & Uraian data & Sumber \\
\hline 1. & Jenis Alat Tangkap & Wawancara Nelayan di Kabupaten Bangka Selatan \\
\hline 2. & $\begin{array}{l}\text { Bahan dan Kontruksi Alat } \\
\text { Tangkap }\end{array}$ & Wawancara Nelayan di Kabupaten Bangka Selatan \\
\hline 3. & Volume Kapal & Wawancara Nelayan di Kabupaten Bangka Selatan \\
\hline 4. & Trip Penangkapan & Wawancara Nelayan di Kabupaten Bangka Selatan \\
\hline 5. & Kelengkapan SIUP dan SIPI & Wawancara Nelayan di Kabupaten Bangka Selatan \\
\hline
\end{tabular}

Data sekunder tersebut diperoleh dari Dinas Pertanian, Pangan dan Perikanan Kabupaten Bangka Selatan dan Badan Pusat Statistik (BPS) Kabupaten Bangka Selatan. Data sekunder yang diambil dalam penelitian disajikan pada Tabel 2.

Tabel 2. Data sekunder yang diambil dalam penelitian

\begin{tabular}{lll}
\hline No. & \multicolumn{1}{c}{ Uraian data } & \multicolumn{1}{c}{ Sumber } \\
\hline 1. & Kabupaten Bangka Selatan dalan Angka tahun 2017 & BPS Kabupaten Bangka Selatan \\
2. & $\begin{array}{l}\text { Data Perikanan Kabupaten Bangka Selatan 2012- } \\
\text { 2016 }\end{array}$ & $\begin{array}{l}\text { Dinas Pertanian, Pangan dan } \\
\text { Perikanan Kab. Basel }\end{array}$ \\
3. & $\begin{array}{l}\text { Laporan Tahunan DPP Kabupaten Bangka Selatan } \\
\text { Bidang Perikanan }\end{array}$ & $\begin{array}{l}\text { Dinas Pertanian, Pangan dan } \\
\text { Perikanan Kab. Basel }\end{array}$ \\
4. & Data Statistik Perikanan & DPP Kabupaten Bangka Selatan \\
\hline
\end{tabular}

Alat yang digunakan dalam penelitian ini yaitu Sofware Statistik untuk mengolah data, alat tulis sebagai media/alat untuk menulis. Bahan yang digunakan yaitu lembaran quisioner sebagai sampel contoh yang akan diolah.

Metode yang digunakan dalam kajian ini adalah metode deskriptif, dengan pengambilan data dilakukan dengan survey, observasi lapangan dan studi pustaka yang relevan. Sedangkan strategi pengembangan perikanan tangkap di Kabupaten Bangka Selatan dilakukan dengan menggunakan analisis kekuatan (strength), kelemahan (weakness), peluang (opportunity) dan ancaman (threat) (SWOT) (Rangkuti, 2015). Beberapa langkah dalam penyusunan strategi pengembangan perikanan tangkap dilakukan tahapan sebagai berikut :

1. Melakukan analisis lingkungan internal (internal factors analysis summary atau IFAS) dan lingkungan eksternal (ekternal factors analysis summary atau EFAS) yang relevan.

2. Melakukan analisis SWOT (strength, weakness, opportunity dan threat).

3. Mengembangkan alternatif strategi dengan menggunakan matrik TOWS.

Kajian mengenai potensi dan tingkat pemanfaatan sumberdaya ikan di Kabupaten Bangka Selatan menggunakan analisis kuantitatif dan analisis deskriptif (Arikunto 2002, Kurniawan 2016). Menurut Jonathan Sarwonno (2006) metode penelitian kuantitatif adalah penelitian ilmiah yang sistematis terhadap bagian-bagian dan fenomena serta hubunganhubungannya. Analisis deskriptif digunakan untuk menjelaskan tentang jenis alat tangkap, kontruksi, volume kapal (GT) serta trip penangkapan per alat tangkap di Kabupaten Bangka Selatan. Analisis deskriptif merupakan metode yang digunakan dalam penelitian sebagai penelitian terapan dengan mengaplikasikan suatu teori untuk memecahkan masalah tertentu.

\section{HASIL}

\section{Daerah Penangkapan Ikan (DPI) Kabupaten Bangka Selatan}

Daerah penangkapan (Fishing ground) tersebar merata di seluruh perairan pesisir Kecamatan di Kabupaten Bangka Selatan. Bagan apung dan bagan tancap terdapat di Kecamatan Pualau Besar, Toboali, Lepar Pongok, Simpang Rimba dan Kepulauan Pongok. Alat tangkap bubu kepiting beroperasi di perairan Kecamatan Pulau Besar, Air Gegas, Toboali, Tukak Sadai, Lepar Pongok dan Pongok. 
Daerah penangkapan udang dogol dan udang rebon terdapat di peairan Toboali, Pulau Besar dan Tukak Sadai. Untuk daerah penangkapan ikan (DPI) jenis cumi-cumi terdapat di perairan Kecamatan, Lepar Pongok, Pongok dan Toboali. Jenis ikan Selar dan Kembung, DPI terdapat di Kecamatan Toboali, Lepar Pongok dan Pongok. Jenis ikan hasil tangkapan kepiting, DPI terdapat di perairan Kecamatan Toboali, Tukak Sadai dan Lepar Pongok. DPI ikan Manyung terdapat di Kecamatan Pulau Besar dan Toboali. Ikan Lemuru DPI terdapat di Perairan Kecamatan Kep. Pongok.

Jenis alat tangkap tersebar merata Sebaran jenis alat tangkap dan jenis ikan hasil tangkapan tersaji pada peta berikut ini:

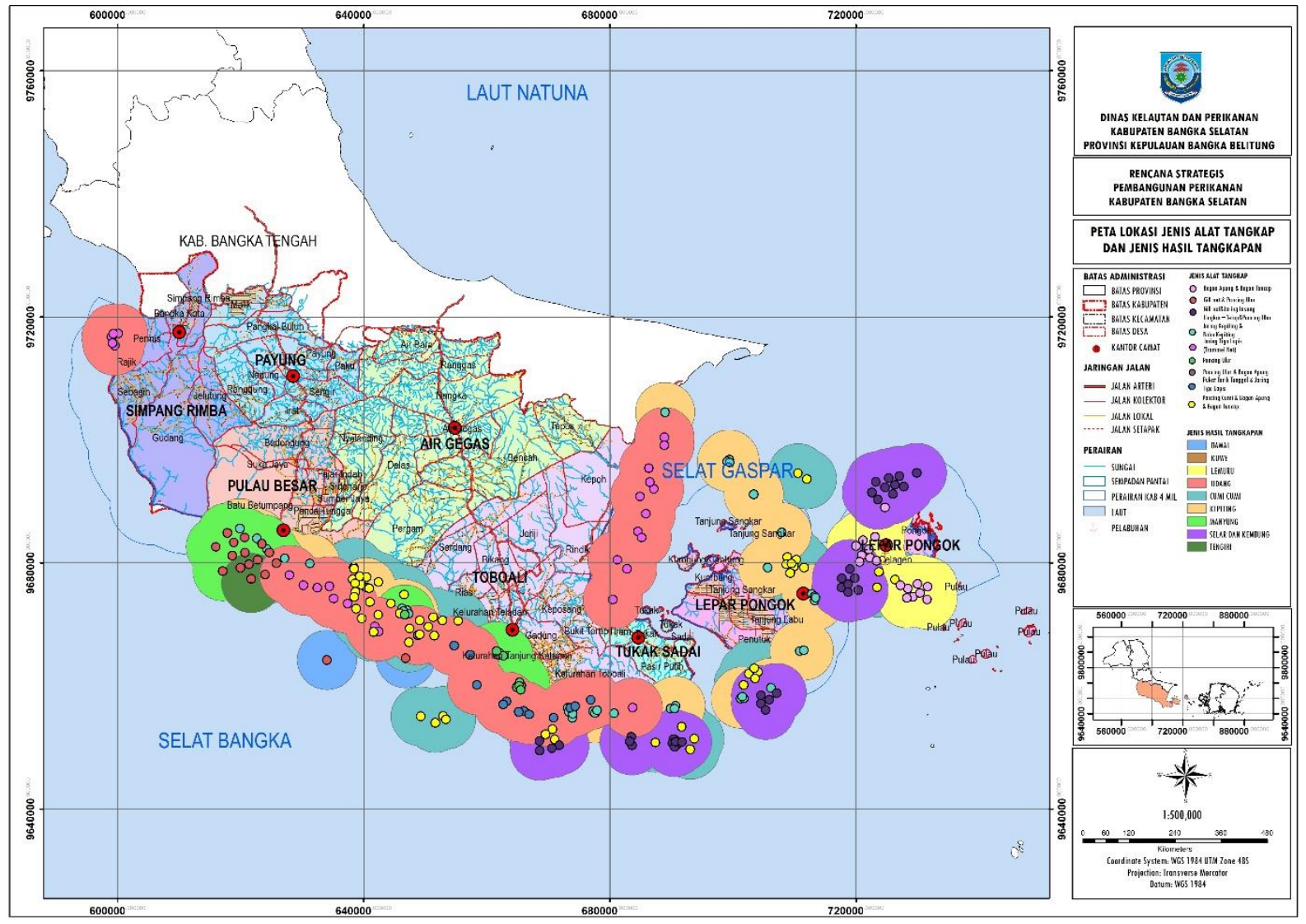

Gambar 1. Peta jenis alat tangkap dan jenis ikan hasil tangkapan di Kab. Basel.

Sumber: Renstra Perikanan Kab. Basel 2017

Dalam 5 tahun terakhir terdapat pertambahan jarak fishing ground (daerah penangkapan) untuk seluruh jenis alat tangkap. Sehingga, terjadi penambahan biaya operasional untuk menuju fishing ground. Sebanyak $43 \%$ nelayan di Kabupaten Bangka Selatan mengalami perubahan fishing ground pertambahan jarak menuju fishing ground. 


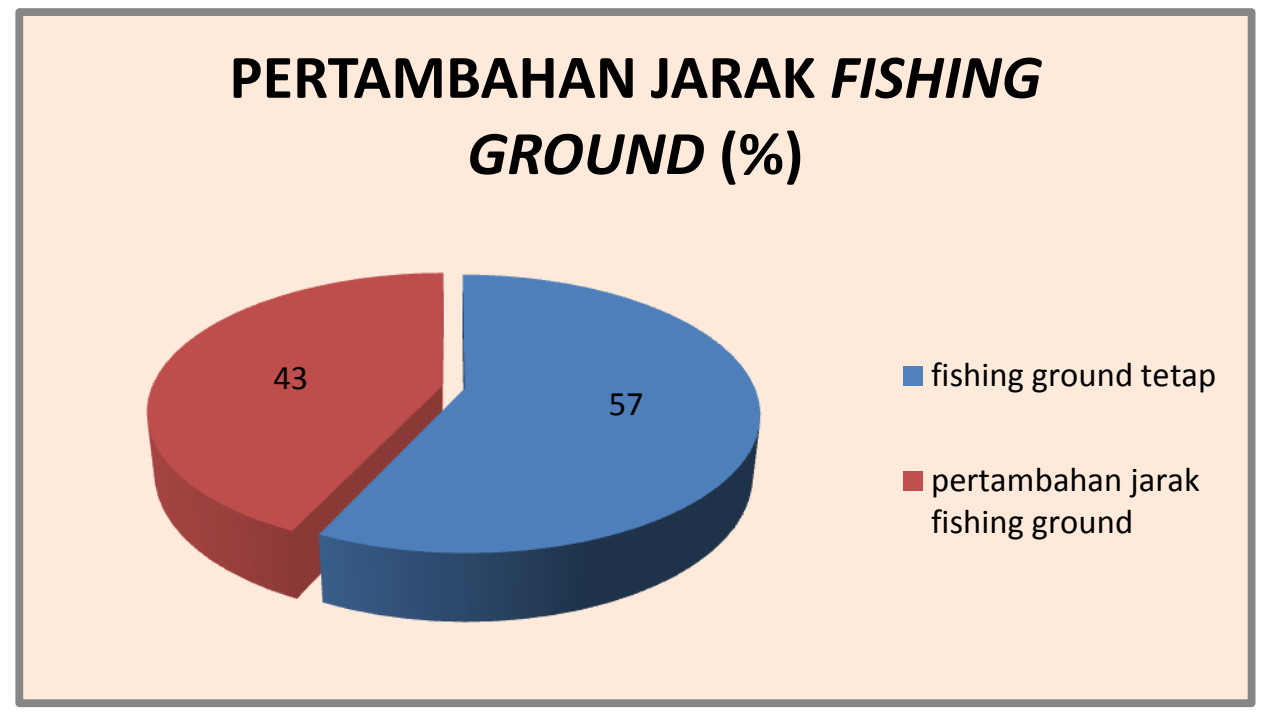

Gambar 2. Pertambahan jarak menuju fishing ground. Sumber: Renstra Perikanan Kab. Basel 2017

\section{Pengaturan Alat Tangkap dan Jumlah Kapal yang Beroperasi di Kabupaten Bangka Selatan}

\section{Illegal Fishing}

Terdapat alat tangkap payang dan pukat pantai yang dilarang digunakan menurut permen KP No 2 tahun 2015 tentang larangan penggunaan alat penangkapan ikan pukat hela (trawls) dan pukat tarik (seine nets) di wilayah pengelolaan perikanan negara republik Indonesia. Pukat pantai sebanyak 132 unit dan payang 1 unit. Alat tangkap ini masih digunakan di Kabupaten Bangka Selatan dikarenakan masih memiliki ijin beroperasi. Perlu adanya solusi untuk mengalihkan alat tangkap pukat tarik dan instansi terkait tidak memberikan ijin perpanjangan penggunaan alat tangkap.

Melihat permasalahan di atas perlu dicari solusi pengalihan alat tangkap agar pemanfaatan sumberdaya ikan dapat dimanfaatkan dengan optimal dan dengan alat tangkap yang ramah lingkungan. Alternatif yang dapat dilakukan dianatanya:

1. Konversi alat tangkap ke alat tangkap yang ramah lingkungan

2. Pelatihan dan pengembangan kapasitas SDM ke bidang lain (keterampilan, bertani atau beternak)

\section{Kelengkapan Administrasi (SIUP, SIPI dan SKPI)}

Nelayan di Kabupaten Bangka Selatan hanya 50\% memiliki Surat izin usaha perikanan (SIUP) dan surat izin penangkapan ikan (SIPI). Ini menunjukkan bahwa kesadaran nelayan di Kabupaten Bangka Selatan untuk melengkapi administrasi masih rendah. Secara tidak langsung akan mengakibatkan sulitnya pengelolaan sektor perikanan tangkap oleh Pemerintah Kabupaten. Untuk itu, perlu adanya strategi pendekatan kepada Nelayan untuk melengkapi kelengkapan administrasi (SIUP, SIPI, SKPI). 


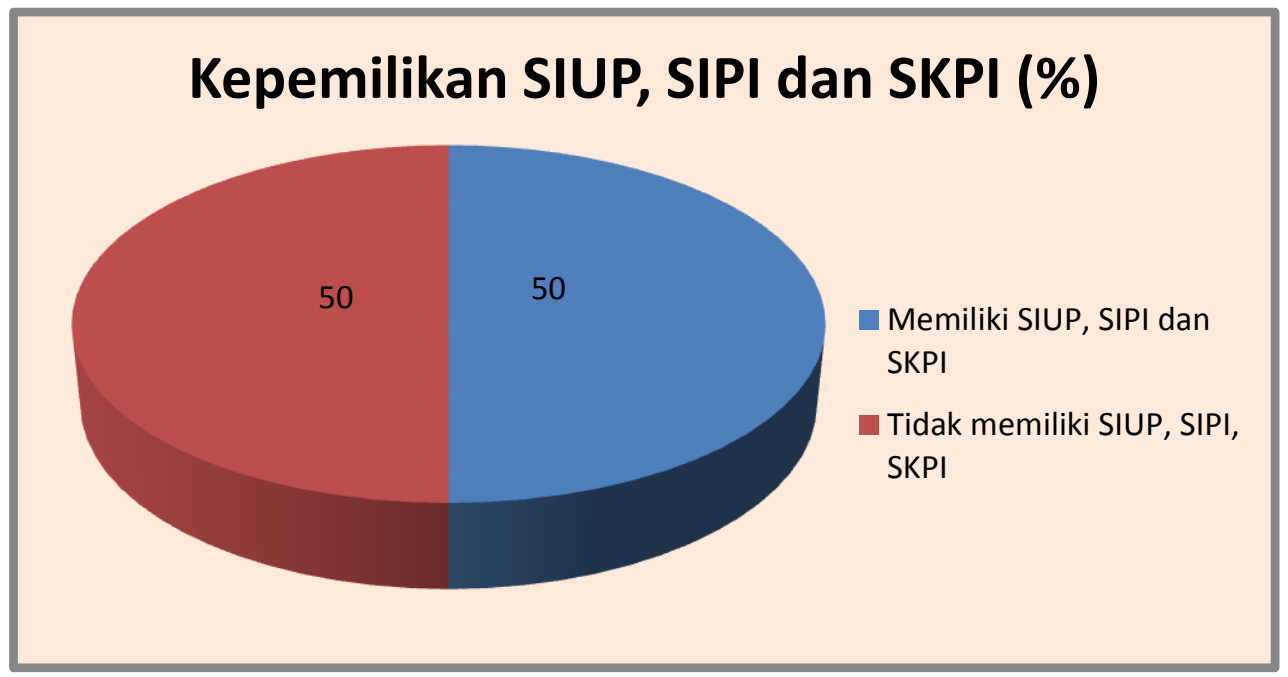

Sumber: Data olahan quisioner Renstra Basel 2017

Gambar 1. Kepemilikan SIUP, SIPI dan SKPI oleh Nelayan di Kab. Basel

Kelompok Nelayan dan pembinaan kelompok nelayan

Hasil diskusi FGD menunjukkan bahwa sebagian besar nelayan di Kabupaten Bangka Selatan masih ketergantungan dengan tengkulak. Untuk itu perlu solusi pemutusan mata rantai pemasaran kepada tengkulak dengan pembinaan nelayan dengan pembentukan kelompok-kelompok nelayan. Tujuan dari pembentukan kelompok-kelompok nelayan adalah untuk meningkatkan kesejahteraan seluruh anggota kelompok.

Dari data FGD Renstra perikanan Kab. Bangka Selatan menunjukkan sebanyak 43\% nelayan di Kabupaten Bangka Selatan tergabung pada kelompok nalayan baik dalam bentuk Kelompok Usaha Bersama (KUB) ataupun Koperasi. Sebanyak 36\% nelayan di Kab. Bangka Selatan telah mendapat pembinaan dari pemerintah daerah.

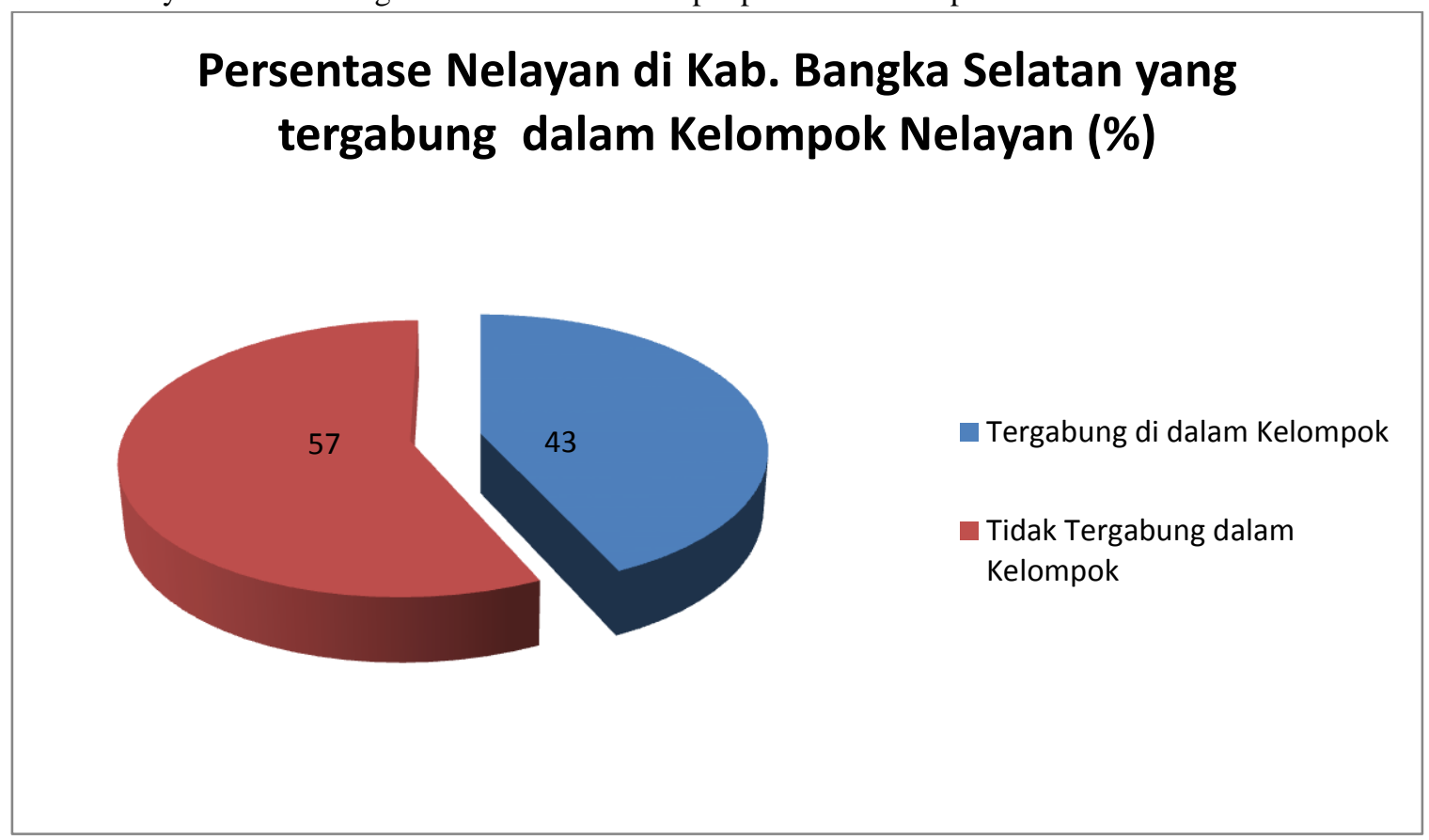

Sumber: Data olahan quisioner Renstra Basel 2017

Gambar 2. Persentase Nelayan yang tergabung dalam kelompok nelayan di Kab. Basel

Analisis SWOT Setelah didapatkan CSF-nya, maka dapat dianalisis faktor lingkungan internal (kekuatan dan kelemahan) dan faktor lingkungan eksternal (peluang dan ancaman). Hasil analisis SWOT terhadap pengembangan perikanan tangkap di Kabupaten Bangka Selatan dapat dilihat pada Tabel 1.

Tabel 3. Rencana strategi perikanan tangkap Kabupaten Bangka Selatan 


\begin{tabular}{|c|c|c|c|}
\hline No. & Kelemahan & No. & Kekuatan \\
\hline 1. & $\begin{array}{l}\text { Nelayan Kabupaten Bangka Selatan masih } \\
\text { berskala kecil memilki ukran kapal }(<5 \mathrm{GT}) \\
\text { dan alat tangkap yang digunakan masih } \\
\text { bersifat tradisional. }\end{array}$ & 1. & $\begin{array}{l}\text { Potensi sumberdaya ikan yang memiliki nilai ekonomi } \\
\text { yang tinggi dan ketersediaannya melimpah. }\end{array}$ \\
\hline 2. & $\begin{array}{l}\text { Keterbatasan SDM baik secara kualitas } \\
\text { maupun kuantitas dalam mengimplementasi } \\
\text { tujuan pengelolaan. }\end{array}$ & 2. & $\begin{array}{l}\text { Adanya dukungan yang kuat dari seluruh elemen baik } \\
\text { pemerintah swasta dan masyarakat untuk } \\
\text { meningkatkan pengembangan perikanan tangkap. }\end{array}$ \\
\hline 3. & $\begin{array}{l}\text { Infrastruktur dan fasilitas yang tesedia belum } \\
\text { bsa memenuhi kebutuhan nelayan. }\end{array}$ & 3. & $\begin{array}{l}\text { Beberapa produk olahan ikan sudah menjadi komoditas } \\
\text { ekspor. }\end{array}$ \\
\hline No. & $\begin{array}{c}\text { Ancaman } \\
\end{array}$ & No. & $\begin{array}{r}\text { Peluang } \\
\end{array}$ \\
\hline 1. & $\begin{array}{l}\text { Penggunaan alat tangkap yang tidak ramah } \\
\text { lingkungan. }\end{array}$ & 1. & $\begin{array}{l}\text { Peningkatan permintaan produk olahan ikan semakin } \\
\text { meningkat setiap tahun. }\end{array}$ \\
\hline 2. & $\begin{array}{l}\text { Pengrusakan terumbu karang dan mangrove } \\
\text { akibat penambangan pesisir dan laut. }\end{array}$ & 2. & $\begin{array}{l}\text { Banyak investor yang mulai melirik potensi perikanan } \\
\text { di Kabupaten Bangka Selatan. }\end{array}$ \\
\hline 3. & $\begin{array}{l}\text { Adanya konflik kepentingan dengan sektor } \\
\text { lainnya. }\end{array}$ & 3. & $\begin{array}{l}\text { Keanekaragaman jenis ikan yang memiliki nilai } \\
\text { ekonomi yang tinggi dapat menjadi komoditas ekspor. }\end{array}$ \\
\hline
\end{tabular}

Alternatif strategi pengembangan diperoleh dengan menggunakan matrik TOWS, yaitu membandingkan antara faktor lingkungan internal dengan faktor lingkungan eksternal. Alternatif strategi yang digunakan adalah SO (strengths opportunities), ST (strengths - threats), WO (weaknesses - opportunities), dan WT (weaknesses - threats). Strategi pengembangan perikanan tangkap di sajikan pada Tabel 2.

Tabel 4. Alternatif Strategi Pengembangan Perikanan Tangkap di Kabupaten Bangka Selatan

\section{No (Kuadran + dan -) Kuadran II (Strategi WO) \\ 1 [W1-W2, O4-O5] pengembangan SDM melalui pemahaman visi, misi Kab. Bangka Selatan bidang perikanan untuk meningkatkan sistem tata kelola pemerintahan \\ 2 [W4, O4] mengoptimalkan kegiatan penangkapan ikan dengan kejelasan zona penangkapan ikan dan zona alinnya (RZWP3K) \\ 3 [W7, O1, O4] membuka pasar baru untuk pemasaran ikan dan produk olahan ikan dengan mengoptimalkan kerjasama yang sudah ada \\ 4 [W6, W8 O1, O4, O6] peningkatan sarana dan prasarana berupa pabrik es dan coolstorage dengan mengoptimalkan kerjasama dengan pihak terkait baik pemerintah pusat ataupun swasta}

\section{No}

Kuadran I (Strategi SO)

1 [S1-3, O1-2] mengoptimalkan tata kelola lembaga dalam memanfaatkan potensi perikanan yang melimpah dengan memanfaatkan tingginya pemintaan pasar

2 [S1-S3, O2] meningkatkan produksi ikan hasil tangkapan unggulan (nilai ekonomi yang tinggi) dengan alat tangkap yang ramah lingkungan

3 [S5,6, O1-4] pengembangan fasilitas dan infrastruktur untuk mendukung peningkatan jumlah produksi ikan hasil tangkapan nelayan

$4 \quad[\mathrm{~S} 1-3, \mathrm{~S} 7, \mathrm{O} 1,2,6]$ pengembangan tambak garam dengan meng optimalkan berbagai kerjasama serta dukungan dari pemerintah daerah untuk memenuhi kebutuhan dan tingginya harga garam sebagai bahan olahan hasil perikanan tangkap

\section{(Kuadran + dan +) \\ Kuadran III (Strategi ST)}

No

[W1, T1,2,3,5] pengoptimalan sarana dan prasarana yang sudah ada untuk meningkatkan produksi perikanan tangkap dengan alat tangkap yang ramah lingkungan

2 [W7,T5] mengaktifkan tempat pelelangan ikan yang sudah ada dan penguatan kelompok nelayan untuk

1

1 [S1-S3, T1-T2] penegakan hukum yang tegas atau melakukan konversi terhadap alat tangkap yang tidak ramah lingkungan dengan adanya komitmen bersama dari pimpinan eksekutif dan legislatif di dalam menciptakan Visi, Misi dan Tujuan penyelenggaraan perikanan di Kab. Bangka Selatan

2 [S2, S4, T1-3] modernisasi armada perikanan tangkap agar dapat bersaing dengan armada dari 
memutus mata rantai dengan tengkulak

3 [W8, T5] meningkatkan kerjasama dengan berbagai sektor dengan memperkuat zona konservasi laut daerah dan memastikan pembangunan bekelanjutan masuk ke dalam kajian rencana dan program di wilayah pesisir dan laut Kab. Bangka Selatan

4 [W1, T1] menyusun tata kelola tempat pelelangan ikan (TPI) yang baik, sehingga dapat mengakomodir kepentingan seluruh stakeholder daerah lain dengan binaan dari pemerintah daerah dan pusat

3 [S1-8, T3,4] penguatan komitmen bersama dengan berbagai pihak untuk menjamin pembangunan berkelanjutan menjadi dasar pembangunan di Kab, Bangka Selatan

4 [S8, T4] mengaktifkan dan meningkatkan jumlah tempat pelelangan ikan (TPI) untuk meningkatkan nilai jual ikan dengan dukungan dari pemerintah daerah dan berbagai elemen masyarakat

\section{PEMBAHASAN}

Berdasarkan hasil analisis, rencana strategi pengembangan perikanan tangkap memiliki beberapa komponen dasar meliputi Kekuatan (strength), Kelemahan (weakness), Peluang (opportunity) dan Ancaman (threat) disajikan pada Tabel 1. Kekuatan merupakan potensi atau kelebihan yang menjadi daya tarik. Kekuatan dalam pengembangan perikanan tangkap di Kabupaten Bangka Selatan, memiliki potensi SDI yang memiliki nilai ekonomi tinggi dan ketersediaanya melimpah. Berdasarkan data dari DPPP Kabupaten Bangka Selatan (2017), jumlah produksi perikanan laut sejak tahun 2012 mencapai 44.733 ton dengan nilai tangkapan ikan RP. 519.329.609,- ditahun 2015 jumlah produksi meningkatkan $\pm 10 \%$ yaitu sebesar 50.302 ton dengan nilai tangkapan ikan sebesar Rp. 1.291.001.815,- dan ditahun 2016 jumlah produksi mengalami penurunan sebesar 41.209 ton dengan nilai tangkapan ikan Rp. 633.568.570,-. Selain itu, jika dilihat nilai MSY sumberdaya ikan diperairan Kabupaten Bangka Selatan terbagi atas ikan pelagis kecil, ikan pelagis besar dan ikan demersal. Menurut Mayu et al., (2018) hasil pendugaan Schaefer nilai MSY ikan pelagis kecil sebesar 31.630 ton/tahun dengan upaya optimum sebesar 88.096 trip/tahun, nilai MSY ikan pelagis besar sebesar 2.340 ton/tahun dengan upaya optimum sebesar 127.465 trip/tahun sedangkan nilai MSY ikan demersal sebesar 16.750 ton/tahun dengan upaya optimum sebesar 244.812 trip/tahun. Selain besarnya potensi yang dimilki, adanya dukungan yang baik dari pemerintah, swasta dan masyarakat dengan hal ini jelas dapat mewujudkan keseimbangan anatara sosial, ekonomi dan berkelanjutan.

Komponen Kelemahan yakni dilihat dari profil kelompok nelayan Kabupaten Bangka Selatan termasuk kategori nelayan kecil, hal ini dilihat dari pendapatan ekonomi, poteni dan cakupan mil dalam melaut. Menurut BPS Kabupaten Bangka Selatan (2017), armada penangkapan yang digunakan dengan ukuran kapal berkisar 5 GT-10 GT, hal ini secara tidak langsung mempengaruhi hasil tangkapan ikan dan pemanfaatan SDI belum maksimal. Selain itu, infrastruktur dan fasilitas yang tersedia belum dapat memenuhi kebutuhan nelayan seperti pelabuhan, pabrik es, garam dan pelayanan adminstrasi. Tabel 1, menjelaskan peluang yang dapat dilihat dalam pengembangan perikanan tangkap di Kabupaten Bangka Selatan ini, sudah adanya investor yang mulai melirik potensi perikanan baik dikembangkan dalam pengolahan hasil perikanan, pariwisata bahari maupun keanekaragaman sumberdaya ikan. Menurut Dinas perindustrian, perdagangan, koperasi dan UMKM Kabupaten Bangka Selatan (2017), olahan hasil perikanan seperti terasi, kemplang, ikan asin, abon ikan dan pekasem digolongkan dalam industri kecil menegah ata IKM. Sedangkan ancaman dalam pengembangan perikanan tangkap ini, adanya pelanggaran yang dilakukan oleh masyarakat sendiri yakni penggunaan alat tangkap yang tidak ramah lingkungan seperti trawl, mengacu Permen KP No. 2 tahun 2015 tentang larangan penggunaan alat penangkapan ikan pukat hela (trawls) dan pukat tarik (seine nets) di wilayah pengelolaan perikanan Negara Republik Indonesia. Selain itu, sektor petambangan telah memberikan kontribusi besar dalam meningkatkan perekonomian daerah. Namun, penempatan dan pemanfaatan lahan yang menimbulkan konflik kepentingan untuk masyarakat dan pemerintahan.

Strategi Pengembangan sektor Perikanan Tangkap

Strategi pengembangan perikanan tangkap terdiri dari beberapa strategi meliputi strategi agresif, stretagi berbenah diri, strategi difensif dan strategi diversidikasi

1. Strategi agresif :

a) Mengoptimalkan tata kelola lembaga dalam memanfaatkan potensi perikanan yang melimpah dengan memanfaatkan tingginya pemintaan pasar

b) Meningkatkan produksi ikan hasil tangkapan unggulan (nilai ekonomi yang tinggi) dengan alat tangkap yang ramah lingkungan

c) Pengembangan tambak garam dengan mengoptimalkan berbagai kerjasama serta dukungan dari pemerintah daerah untuk memenuhi kebutuhan dan tingginya harga garam sebagai bahan untuk mengolah hasil perikanan tangkap

d) Pengembangan fasilitas dan infrastruktur untuk mendukung peningkatan jumlah produksi ikan hasil tangkapan nelayan

\section{Strategi berbenah diri:}


a) Pengembangan SDM melalui pemahaman visi, misi Kab. Bangka Selatan bidang perikanan untuk meningkatkan sistem tata kelola pemerintahan

b) Mengoptimalkan kegiatan penangkapan ikan dengan kejelasan zona penangkapan ikan dan zona lainnya (RZWP3K)

c) Membuka pasar baru untuk pemasaran ikan dan produk olahan ikan dengan mengoptimalkan kerjasama yang sudah ada

d) Peningkatan sarana dan prasarana berupa pabrik es dan coolstorage dengan mengoptimalkan kerjasama dengan pihak terkait baik pemerintah pusat ataupun swasta

3. Strategi diversifikasi:

a) Penegakan hukum yang tegas atau melakukan konversi terhadap alat tangkap yang tidak ramah lingkungan dengan adanya komitmen bersama dari pimpinan eksekutif dan legislatif di dalam menciptakan Visi, Misi dan Tujuan penyelenggaraan perikanan di Kab. Bangka Selatan

b) Modernisasi armada perikanan tangkap agar dapat bersaing dengan armada dari daerah lain dengan binaan dari pemerintah daerah dan pusat

c) Penguatan komitmen bersama dengan berbagai pihak untuk menjamin pembangunan berkelanjutan menjadi dasar pembangunan di Kab, Bangka Selatan

d) Mengaktifkan dan meningkatkan jumlah tempat pelelangan ikan (TPI) untuk meningkatkan nilai jual ikan serta penguatan kelompok-kelompok nelayan dengan dukungan dari pemerintah daerah dan berbagai elemen masyarakat

4. Strategi difensif:

a) Pengoptimalan sarana dan prasarana yang sudah ada untuk meningkatkan produksi perikanan tangkap dengan alat tangkap yang ramah lingkungan

b) Mengaktifkan tempat pelelangan ikan yang sudah ada dan penguatan kelompok nelayan untuk memutus mata rantai dengan tengkulak

c) Meningkatkan kerjasama dengan berbagai sektor dengan memperkuat zona konservasi laut daerah dan memastikan pembangunan bekelanjutan masuk ke dalam kajian rencana dan program di wilayah pesisir dan laut Kab. Bangka Selatan

d) Menyusun tata kelola tempat pelelangan ikan (TPI) yang baik, sehingga dapat mengakomodir kepentingan seluruh stakeholder

\section{KESIMPULAN DAN SARAN}

\section{Kesimpulan}

Berdasarkan kajian analisis SWOT Prioritas strategi pengembangan perikanan tangkap di Kabupaten Bangka Selatan adalah sebagai berikut: a. Strategi pengembangan pariwisata berbasis sosial, ekonomi dan berkelanjutan; b. Strategi peningkatan dan pengembangan kualitas sumberdaya manusia; c. Strategi promosi akan potensi sumberdaya ikan unggulan untuk dikembangkan menjadi produk ekspor; d. Strategi peningkatan sarana, prasarana dan fasilitas pendukung pengembangan perikanan.

Saran

Dalam pengembangan sektor perikanan khususnya perikanan tangkap di Kabupaten Bangka Selatan untuk memaksimalkan kekuatan-kekuatan dan peluang yang dimiliki organisasi dalam upaya mengembangkan dan meningkatkan ekonomi daerah sehingga dapat mewujudkan keseimbangan antara sosial, ekonomi dan keberlanjutan.

\section{UCAPAN TERIMAKASIH}

Penulis mengucapkan terimakasih kepada para rekan-rekan staf pengajar dan mahasiswa program studi manajemen sumberdaya perairan yang telah memberikan saran, dukungan dan ikut serta selama proses penyusunan penelitian ini. Ucapan terimakasih juga disampaikan kepada orang tua dan keluarga.

\section{DAFTAR PUSTKA}

Arikunto, S. (2002). Metodologi penelitian.

Badan Pusat Statistik. 2017. Kabupaten Bangka Selatan dalam Angka 2017. Katalog : 280 Hlm. 
Dinas Pertanian, Pangan, Perikanan Kabupaten Bangka Selatan. 2017. Data Tahunan Statistik Perikanan Tangkap dan Perikanan Budidaya. Dinas Pertanian, Pangan, Perikanan Kabupaten Bangka Selatan.

Dinas UMKM. 2017. Data Tahunan Statistik Perikanan Tangkap dan Perikanan Budidaya. Dinas Pertanian, Pangan, Perikanan Kabupaten Bangka Selatan.

Febrianto, A., \& Kurniawan, K. (2015). Pengaruh Logam Berat Pb Limbah Aktifitas Penambangan Timah Terhadap Kualitas Air Laut di Wilayah Penangkapan Cumi-Cumi Kabupaten Bangka Selatan. AQUATIC, 8(2).

Kurniawan, S., \& Sasongko, D. P. (2014). Pengaruh Aktifitas Penambangan Timah Terhadap Kualitas Air Laut Dan Ikan Kakap Merah Di Wilayah Pesisir Kabupaten Bangka. Jurnal Akuatik Sumberdaya Perairan, 2(1), 21-23.

Kurniawan, K., Suhandi, S., \& Natiqoh, N. U. (2016). Analisis efektifitas produksi cumi cumi (Loligo Sp.) pada alat tangkap bagan tancap menggunakan lampu celup dalam air dan lampu di atas permukaan air di Desa Rebo Kab. Bangka. Akuatik: Jurnal Sumberdaya Perairan, 10(2), 56-61.

Mayu, D. H., Kurniawan, K., \& Febrianto, A. (2018). ANALISIS POTENSI DAN TINGKAT PEMANFAATAN SUMBERDAYA IKAN DI PERAIRAN KABUPATEN BANGKA SELATAN. Jurnal Perikanan Tangkap: Indonesian Journal of Capture Fisheries, 2(1), 30-41.Rangkuti, F. 2015. Personal SWOT Analysis. PT Gramedia Pustaka Utama : Jakarta.

Pertiwi, 2011. Komposisi Jenis dan Ukuran yang Tertangkap dengan Sero dan Pukat Pantai di Perairan Kota Palopo, Provinsi Sulawesi Selatan.[SKripsi]. Universitas Hasanuddin. Makasar.

Sarwono, J. (2012). Metode Riset Skripsi Pendekatan Kuantitatif (Menggunakan Prosedur SPSS): Tuntunan Praktis dalam Menyusun Skripsi. 